\title{
A Rare Cause of Heart Failure Treated by Heart Transplantation: Noncompaction of the Ventricular Myocardium
}

\author{
Julien Bordes, ${ }^{1}$ Bertrand Jop, ${ }^{2}$ Sandrine Imbert, ${ }^{2}$ Sami Hraiech, ${ }^{3}$ Frédéric Collard, ${ }^{2}$ \\ and François Kerbaul ${ }^{3}$ \\ ${ }^{1}$ Department of Intensive Care, Sainte Anne Hospital, 83800 Toulon, France \\ ${ }^{2}$ Department of Cardiac Surgery, La Timone Hospital, 13000 Marseille, France \\ ${ }^{3}$ Department of Anesthesia and Intensive Care Unit, La Timone Hospital, 13000 Marseille, France
}

Correspondence should be addressed to Julien Bordes, bordes.julien@neuf.fr

Received 21 September 2009; Accepted 14 December 2009

Recommended by John A. Elefteriades

Noncompaction of the ventricular myocardium is a rare cardiomyopathy due to an arrest of myocardial morphogenesis. The characteristic echocardiographic findings are prominent myocardial trabeculations and deep intertrabecular spaces communicating with the left ventricular cavity. The clinical manifestations include heart failure (HF) signs, ventricular arrhythmias, and cardioembolic events. We describe an illustrative case of noncompaction of the ventricular myocardium associated with bicuspid aortic valve, a 42-year-old male presenting a refractory acute heart failure successfully treated by emergency heart transplantation.

Copyright ( $) 2009$ Julien Bordes et al. This is an open access article distributed under the Creative Commons Attribution License, which permits unrestricted use, distribution, and reproduction in any medium, provided the original work is properly cited.

\section{Introduction}

Noncompaction of the ventricular myocardium (NVM) is a recently described cardiomyopathy. It is an anomaly of myocardial morphogenesis that leads to persistent prominent ventricular trabeculations and deep intertrabecular recesses communicating with the ventricular cavity [1]. The prognosis is poor and heart transplantation has to be considered in patients with severe symptoms [2]. This disease is rare and may be undiagnosed. Herein we report a late presenting case of NVM with end stage congestive heart failure, successfully treated with heart transplantation.

\section{Case Presentation}

A 42-year-old man was referred in for evaluation of progressive dyspnea. He had a history of aortic bicuspid valve, with a poor medical followup. A transesophageal echocardiography demonstrated the aortic bicuspidy with grade III aortic insufficiency. The left ventricle was dilated with an ejection fraction of $40 \%$. A surgical valve repair was proposed though the patient refused surgery. After 3 months, the patient was admitted to hospital emergently with congestive heart failure.
Diuretic and dobutamine infusions were started, as well as amiodarone after an episode of ventricular fibrillation. Despite this medical treatment, his condition worsened and he was transferred to our cardiac surgical intensive care unit.

On admission, the heart rate was $89 / \mathrm{min}$ and the arterial pressure was $80 / 50 \mathrm{mmHg}$ on dobutamine $20 \mu \mathrm{g} / \mathrm{kg} / \mathrm{min}$. The patient's oxygen saturation was $99 \%$ on room air. The transthoracic echocardiography showed severely depressed left ventricular systolic function with an ejection fraction of $25 \%$. The left ventricle was dilated with a severe functional mitral regurgitation (Figure 1). Although previous echocardiography demonstrated significant aortic insuficiency, the aortic regurgitation was measured minimal (Figure 1). In addition, repeat echocardiography visualized prominent ventricular trabeculations in left ventricle, predominant to apical and mid-inferior areas (Figure 2). The maximal end systolic ratio of noncompacted to compacted layers was greater than 2 . The right ventricle appeared to be more heavily trabeculated than normal while color Doppler displayed flow within the deep intertrabecular recesses (Figure 2). These findings were consistent with the diagnosis of ventricular noncompaction. 


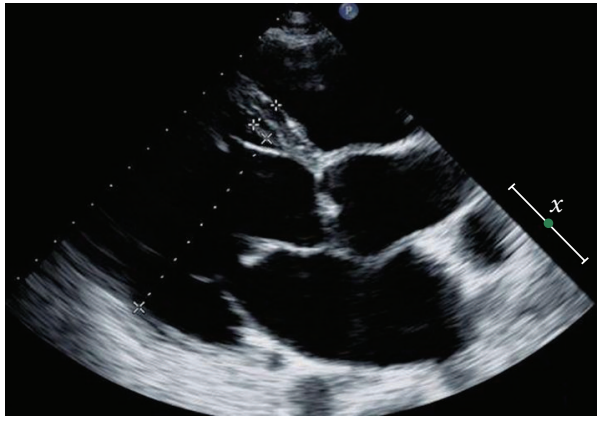

(a)

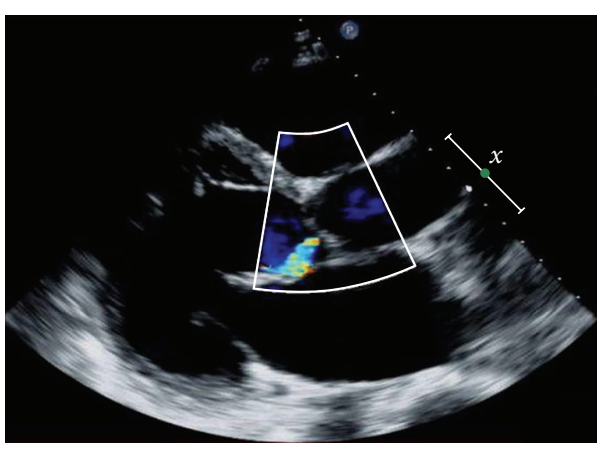

(b)

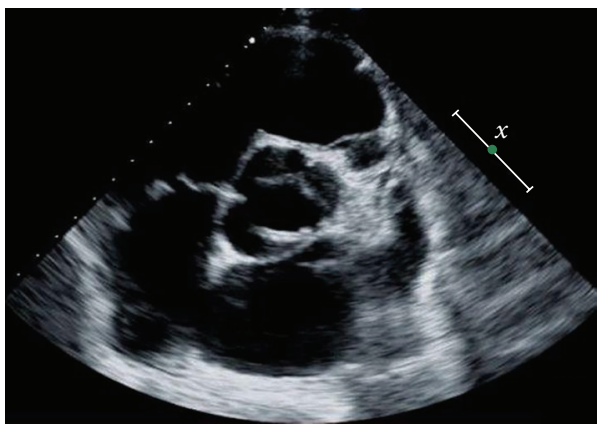

(c)

Figure 1: Transthoracic echocardiography. (a) Parasternal longaxis view, the left ventricule telediastolic diameter is $80 \mathrm{~mm}$. (b) Parasternal long-axis view, aortic regurgitation. (c) Short-axis view at the level of the aorta, bicuspid aorti valve.

The patient's cardiac status continued to worsen and medical therapy was intensified. Epinephrine was added to the dobutamine infusion and hemofiltration was initiated. It was decided to place the patient on urgent priority heart transplant list. Subsequently, the patient underwent a heart transplantation three days after admission. Extracorporeal circulatory support was necessary for 24 hours post-operatively. The patient was extubated on postoperative day 6. He was discharged from the intensive care unit 17 days post-transplantation and he remained well for the subsequent 2 months.

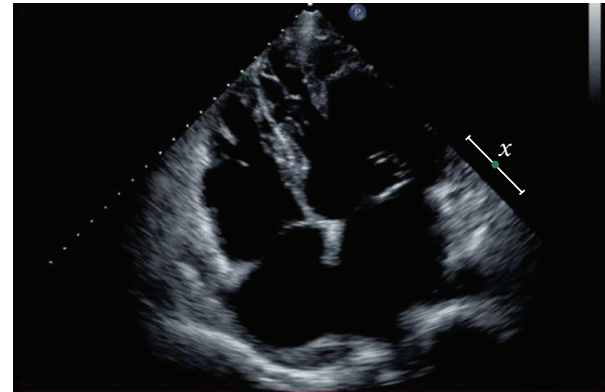

(a)

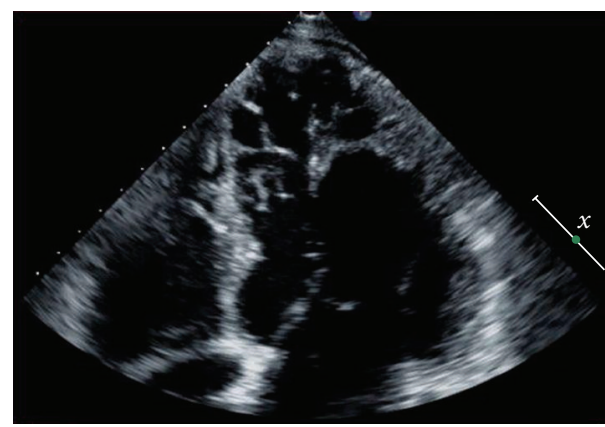

(b)

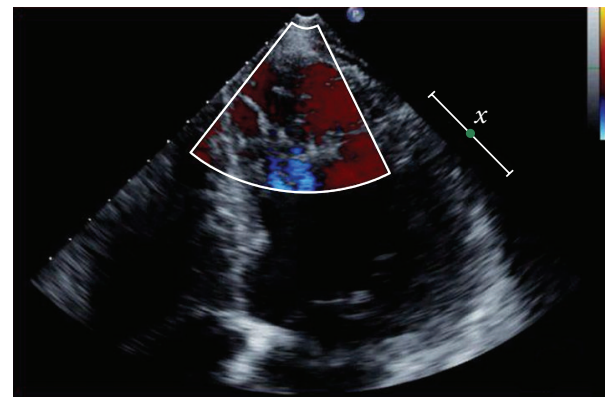

(c)

Figure 2: Transthoracic echocardiography. (a) and (b) Apical four-chamber view, characteristic, multiple, prominent muscular trabeculations and intertrabecular recesses. (c) Color Doppler mode, blood flow within the deep intertrabecular recesses.

\section{Discussion}

Noncompaction of the ventricular myocardium (sometimes referred as "spongy myocardium") is a rare cardiomyopathy recently categorized as a primary genetic cardiomyopathy [3]. This abnormality is believed to represent an arrest in endomyocardial morphogenesis. The anatomical aspect is characterized by persistent prominent ventricular trabeculations and deep intertrabecular recesses communicating with the ventricular cavity [1]. Men appear to be affected more often than women with male patients accounting for 56$82 \%$ of cases [4]. In the largest series of patients with isolated noncompaction ventricles, the prevalence was $0.014 \%$ [5]. 
The disease involves the left ventricular myocardium, but right ventricular involvement is not uncommon [6]. Noncompaction of the ventricular myocardium may be isolated, but it can often coexist various cardiac or extracardiac anomalies, as in our case (bicuspid aortic valve). Literature reports that NVM with bicuspid aortic valve and aortic regurgitation seems to have a poor prognosis [7]. A pathological study of 14 cases of infants with NVM and unexpected death has reported a high incidence of valvular anomalies (5/14 cases, 35\%) [6].

The clinical manifestations include systolic and diastolic dysfunction associated with heart failure signs, ventricular arrhythmias and cardioembolic events [4]. Symptoms vary among patients, ranging from asymptomatic left ventricular dysfunction to terminal heart failure. The prognosis of symptomatic patients is poor. In a series published by Ritter et al., mortality in adults during a 6 year follow-up period after onset of symptoms exceeded $47 \%$ [8]. The common causes of death are intractable heart failure or sudden cardiac death due to ventricular arrythmias.

Diagnosis can be made by two dimension and color Doppler echocardiography. Four morphological criteria have been defined: (1) absence of coexisting cardiac abnormalities (to define an isolated NVM), (2) maximal end systolic ratio of noncompacted to compacted layers superior to 2, (3) predominant localisation of the pathology to mid-lateral, apical, and mid-inferior areas, (4) colour Doppler evidence of deep perfused intertrabecular recesses [9]. Magnetic resonance imaging, computed tomography and ventriculography can also be utilized [4].

Unfortunately, as demonstrated in our case, NVM is often misdiagnosed since it is not a prevalent disease. Frequently, during routine echocardiographic evaluation, the disease is identified as an incidental finding, which leads to the diagnosis being made several months to years after the onset of symptoms. Szymanski et al. published a case of NVM revealed by a ventricular arrhythmia; such arrhythmias can justify implantation of a cardioverter-defibrillator. This patient diagnosed with idiopathic cardiomyopathy, has been managed for many years with nonspecific treatment [10].

The management of NVM is not specific. Anticoagulation is warranted in presence of thromboembolic complications [11]. Standard medical therapy for ventricular dysfunction does not differ from other form of chronic heart failure. As in our case, cardiac transplantation has to be considered for those with refractory heart failure, although it is not a frequent therapeutic eventuality, from 4 to $12 \%$ of patients of published series $[2,4]$. According to our data only 8 adult patients with NVM have been reported to have undergone heart transplantation.

\section{Conclusion}

Noncompaction of the ventricular myocardium is a rare disease often unrecognized because not widely known. Nevertheless, this cardiopathy can be accompanied by three major cardiac risks: heart failure, ventricular arrhythmias, and endocardial clot with systemic embolization. Our case report emphasizes the need for practitioner to recognize this disease not to miss a potential life-threatening pathology.

\section{References}

[1] T. K. Chin, J. K. Perloff, R. G. Williams, K. Jue, and R. Mohrmann, "Isolated noncompaction of left ventricular myocardium. A study of eight cases," Circulation, vol. 82, no. 2, pp. 507-513, 1990.

[2] V. Conraads, B. Paelinck, A. Vorlat, M. Goethals, W. Jacobs, and C. Vrints, "Isolated non-compaction of the left ventricle: a rare indication for transplantation," Journal of Heart and Lung Transplantation, vol. 20, no. 8, pp. 904-907, 2001.

[3] B. J. Maron, J. A. Towbin, G. Thiene, et al., "Contemporary definitions and classification of the cardiomyopathies: an American Heart Association Scientific Statement from the Council on Clinical Cardiology, Heart Failure and Transplantation Committee; Quality of Care and Outcomes Research and Functional Genomics and Translational Biology Interdisciplinary Working Groups; and Council on Epidemiology and Prevention," Circulation, vol. 113, no. 14, pp. 1807-1816, 2006.

[4] B. C. Weiford, V. D. Subbarao, and K. M. Mulhern, "Noncompaction of the ventricular myocardium," Circulation, vol. 109, no. 24, pp. 2965-2971, 2004.

[5] E. N. Oechslin, C. H. Attenhofer Jost, J. R. Rojas, P. A. Kaufmann, and R. Jenni, "Long-term follow-up of 34 adults with isolated left ventricular noncompaction: a distinct cardiomyopathy with poor prognosis," Journal of the American College of Cardiology, vol. 36, no. 2, pp. 493-500, 2000.

[6] A. Burke, E. Mont, R. Kutys, and R. Virmani, "Left ventricular noncompaction: a pathological study of 14 cases," Human Pathology, vol. 36, no. 4, pp. 403-411, 2005.

[7] Y. Cavusoglu, N. Ata, B. Timuralp, et al., "Noncompaction of the ventricular myocardium: report of two cases with bicuspid aortic valve demonstrating poor prognosis and with prominent right ventricular involvement," Echocardiography, vol. 20, no. 4, pp. 379-383, 2003.

[8] M. Ritter, E. Oechslin, G. Sutsch, C. Attenhofer, J. Schneider, and R. Jenni, "Isolated noncompaction of the myocardium in adults," Mayo Clinic Proceedings, vol. 72, no. 1, pp. 26-31, 1997.

[9] R. Jenni, E. Oechslin, J. Schneider, C. Attenhofer Jost, and P. A. Kaufmann, "Echocardiographic and pathoanatomical characteristics of isolated left ventricular non-compaction: a step towards classification as a distinct cardiomyopathy," Heart, vol. 86, no. 6, pp. 666-671, 2001.

[10] C. Szymanski, A. Otmani, L. Leborgne, et al., "Ventricular tachycardia revealed by a left ventricular non-compaction," Annales de Cardiologie et d'Angeiologie, vol. 56, no. 6, pp. 319323, 2007.

[11] F. Thuny, E. Philip, K. Caucino, et al., "Isolated noncompaction of the left ventricle," Archives des Maladies du Coeur et des Vaisseaux, vol. 96, no. 4, pp. 339-343, 2003. 


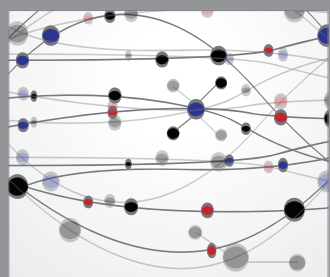

The Scientific World Journal
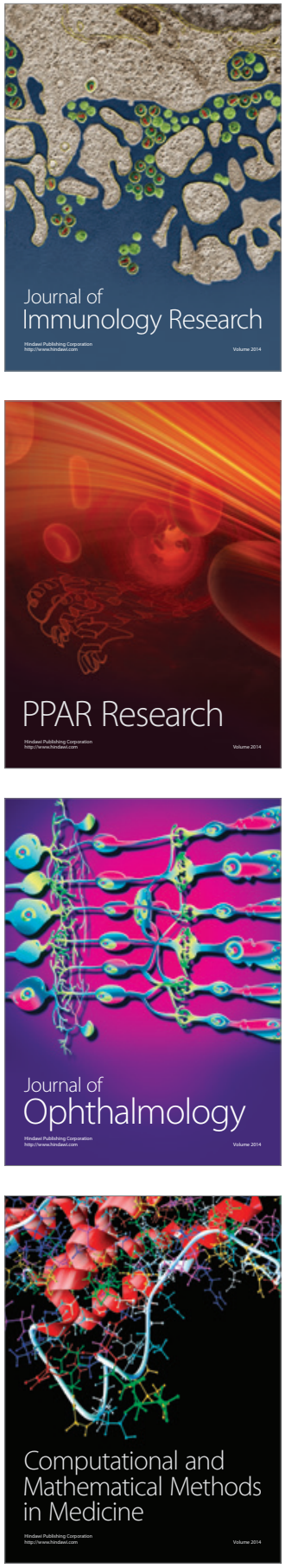

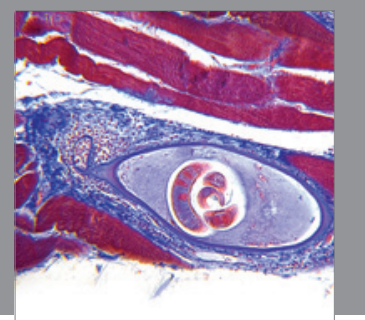

Gastroenterology

Research and Practice
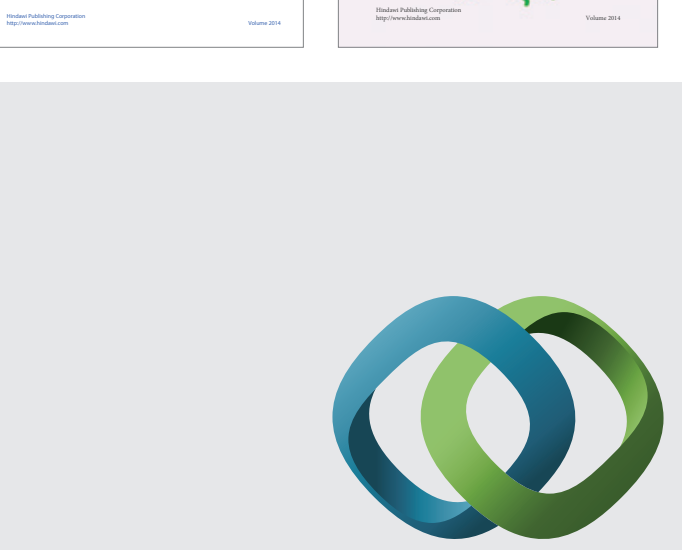

\section{Hindawi}

Submit your manuscripts at

http://www.hindawi.com
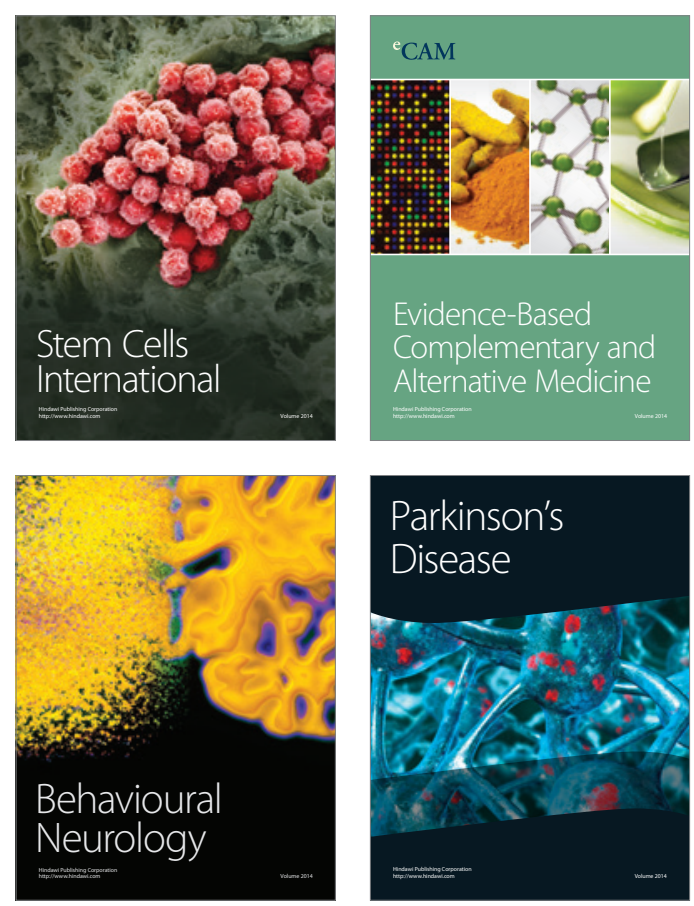

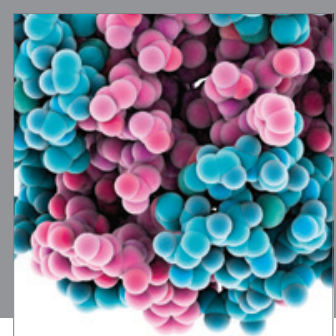

Journal of
Diabetes Research

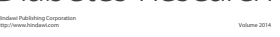

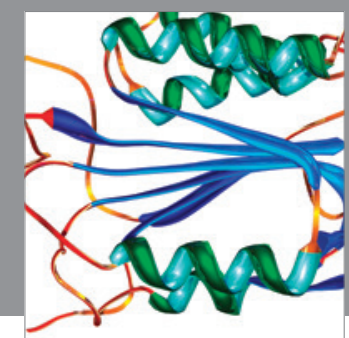

Disease Markers
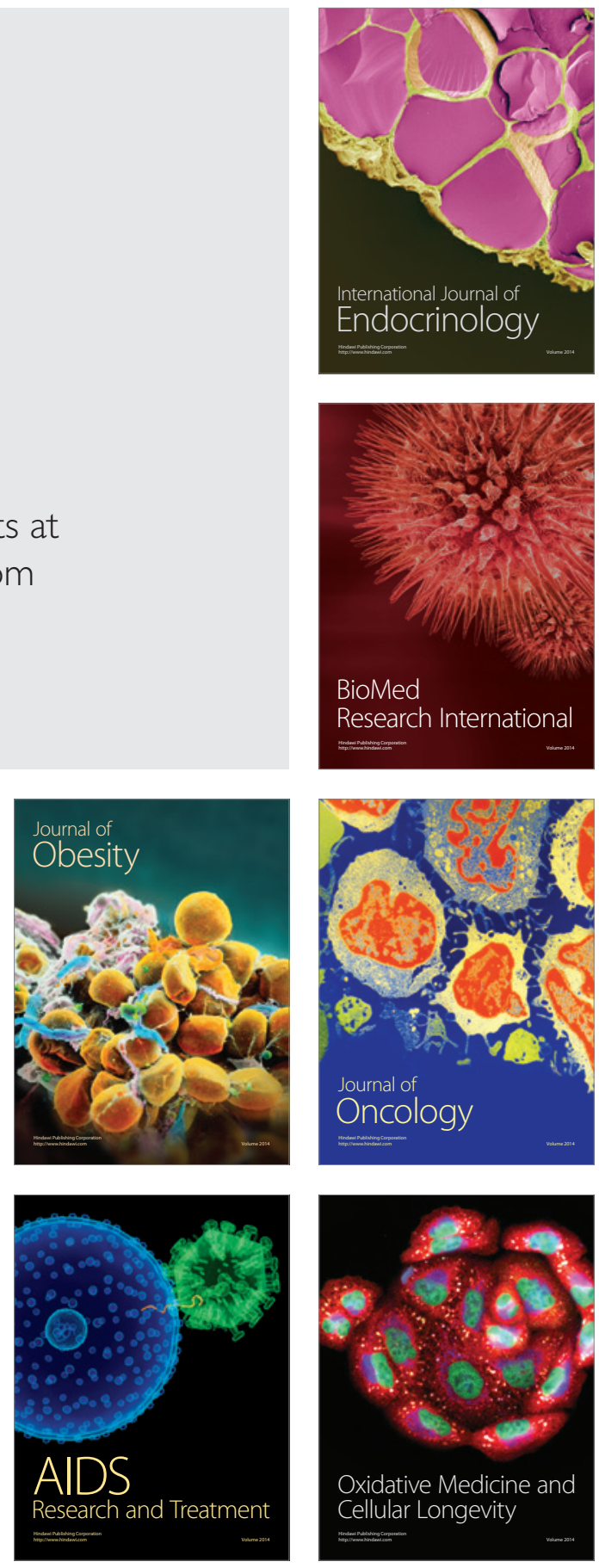